\title{
ANAESTHESIA IN DYSTROPHIA MYOTONIA
}

\author{
F. C. Haley, M.D.*
}

Dystrophia myotonia (or myotonia dystrophia) is a generalized disease. The primary lesion is unknown. It is characterized by an instability of the muscle end plate, which results in ready depolarization of the end plate with a consequent muscle contraction. This ready depolarization and contraction causes the symptoms of myotonia, such as the typical myotonic contraction following mechanical stimulation. These patients also show a remarkable inability to release the hand grip. The myotonia is often aggravated by cold or excitement. As an end result of the prolonged stimulation, atrophy of the muscles gradually develops. This is most obvious in the sternomastoids, and one of the early symptoms is trouble in lifting the head from the pillow. Atrophy of the facial muscles of ten produces a hatchet face. The weakness spreads gradually throughout the body and the result is a generalized malfunction. Articulation and phonation are poor although swallowing is not affected. Weakness of the intercostal muscles, the abdomen, and the diaphragm reduce the efficiency of breathing. A similar myoneural lesion in the heart causes defects of conduction and rhythm. There is of ten a depression of adrenal cortical function. As part of the generalized disease, testicular atrophy, baldness, cataracts, and mental deterioration have been mentioned. Patients may show vague symptoms associated with mild hypofunction of the pituitary gland, thyroid, adrenal, and pancreas. The incidence of dystrophia myotonia is said to be one in a thousand of the population. It is a heredo-familial disease, showing anticipation in successive generations, i.e., a patient with the full-blown disease at the age of 20 often has a parent similarly afflicted by the age of 40 , and a grandparent who showed minimal stigmata such as cataracts or early baldness. ${ }^{1}$

Patients with advanced stages of this disease usually show a marked decrease in the respiratory minute volume, vital capacity, and the maximum breathing capacity, due to the muscular atrophy and secondary fixation of the chest wall. Usually they have a chronic productive cough due to inability to clear their lungs of secretions. The abnormal cardiac rhythm and the common defect of the adrenal cortex may further aggravate their condition. 'In addition to this, the condition that precipitated surgery mäy make them worse candidates for anaesthesia. As a further complication many of these patients have been treated with multiple medications, i.e., quinine, heavy doses of steroids, or ion exchange resins. These medications seem to be of little value

Dundee $^{2}$ in 1952 reported three cases of myotonia dystrophia, of whom two received an anaesthetic. The first was a 140-pound 56-year-old woman who received $10 \mathrm{mg}$. of morphine and $0.6 \mathrm{mg}$. of atropine followed by $0.5 \mathrm{gm}$. of thiopental. She was apnoeic for 10 minutes, normal respiration returned in 30

* Department of Anaesthesia, University of Alberta Hospital, Edmonton, Alberta. 
minutes, and there was no response to carbon dioxide. There had been no assessment of her respiratory condition prior to anaesthesia. The second case was a 112-pound 31-year-old man who received $21 \mathrm{mg}$. of Pantopon and $0.4 \mathrm{mg}$. of hyoscine followed by $250 \mathrm{mg}$. of thiopental, which produced apnoea for three minutes. He was intubated without relaxant. There was no report of his pulmonary function. The third case did not have an operation but was a myotonia dystrophia patient who showed some depression of respiration from $50 \mathrm{mg}$. of thiopental given intravenously, without loss of consciousness. (Normal persons are said to show a transient stimulation of respiration with this dose.) From these three cases Dr. Dundee decided that thiopental produced a severe depression of respiration in patients with myotonia dystrophia and stated that these patients should not receive more than $100 \mathrm{mg}$. of thiopental. He also stated: "such is the rarity of dystrophia myotonia and of its sufferers coming into operation that it is not considered necessary to give a detailed description of this disease."

Leon $\mathrm{Kaufman}^{3}$ in 1960 reviewed the literature to that time. Of 25 documented general anaesthetics in his series, there were five instances of respiratory depression and four deaths. The depressed patients had all received multiple medications and Dr. Kaufman reported that the result of these medications in patients with markedly reduced maximum breathing capacity and tidal volume was precisely as one could anticipate. He also mentioned two patients who died without the benefit of anaesthesia or surgery. Dr. Kaufman stated that the preoperative assessment of lung function was very inportant, particularly the measurement of vital capacity, the maximum breathing capacity, and the one-second functional expiratory capacity. He also recommended fluoroscopy to ascertain the function of the diaphragms, and assessment of the cardiovascular and endocrine systems. He felt that it was mandatory to cancel operation if a respiratory infection was present. In the postoperative period, assisted ventilation and possible tracheostomy were recommended. He also recommended 300 to $600 \mathrm{mg}$. of quinine hydrochloride if myotonia was present as a result of cold or excitement. He noted that spinal and local anaesthesia were not useful in providing relaxation, but local procaine would block the myotonic response. He recommended the use of competitive relaxants and avoidance of depolarizing agents. The use of neostigmine was considered inadvisable as it increased the myotonic response.

Taverner ${ }^{4}$ in 1960 concurred that the anaesthetic problems are those of any patient with severe muscle weakness. Ventilation is impaired by the myotonia, and postoperative respiratory obstruction is a particular hazard because of the greatly weakened neck musculature. He recommended minimal premedication, with expert anaesthetic technique, including adequate ventilation, and felt that this was of greater importance than the choice of anaesthetic agent.

In the past ten years there have been 11 patients admitted to the University of Alberta Hospital with a proven diagnosis of myotonia dystrophia. Of these, six patients have received a total of nine anaesthetics. Two of these were administered by the author.

CASE 1

This patient was an $83 \frac{3}{4}$ pound female in whom the diagnosis was made in 1947 at the age of 32 . She was readmitted in 1950 in an advanced stage, and also 4 months pregnant. She 
was anaesthetized for hysterotomy and sterilization. The preoperative medication of $8 \mathrm{mg}$. of morphine and $0.6 \mathrm{mg}$. of atropine presumably was effective. Anaesthesia was induced with $200 \mathrm{mg}$. of thiopental, and maintained with nitrous oxide 5 liters and oxygen 3 liters per minute in a semi-open system, with in termittent thiopental to a total of $500 \mathrm{mg}$. Blood pressure was recorded as $90 / 60$, rising to $100 / 60$, with a pulse of 74 . She received two doses of Ergometrine $0.25 \mathrm{mg}$. intravenously during the anaesthetic. She returned to the ward unconscious, cyanosed, with a pulse of 64 per minute, respirations 20 and shallow. Five minutes later the blood pressure was $93 / 50$, and the patient received $100 \mathrm{mg}$. of meperidine; the results were not noted. She was later discharged.

This patient was readmitted in September, 1951, with menorrhagia and was anaesthetized for an abdominal hysterectomy. The preoperative sedation was phenobarbital $60 \mathrm{mg}$. at bedtime, and meperidine $50 \mathrm{mg}$. and hyoscine $0.4 \mathrm{mg}$. one hour prior to operation. The induction agent was thiopental $750 \mathrm{mg}$. Anaesthesia was maintained with nitrous oxide - oxygen and she also received $2.5 \mathrm{ml}$. of a curare preparation "Intocostrin." The course of anaesthesia was uneventful, and there was no mention of assisted respiration. On return to the ward after operation the pulse was 52 and the respirations 20 per minute. Ten minutes later the blood pressure was $80 / 30$ and the foot of the bed was elevated, blankets and hot water bottles applied, and $500 \mathrm{ml}$. of blood started. Forty minutes later the blood pressure was 120/70 and the airway removed because of vomiting. An hour after that, there was no blood pressure obtainable. She was given nikethamide (Coramine $($ ) $5 \mathrm{ml}$. intramuscularly and 30 minutes late when there was still no blood pressure obtainable nasal oxygen was started at 6 liters per minute. After another 15 minutes the patient was responding and 30 minutes later the oxygen was reduced to 4 liters per minute. The blood pressure rose to $112 / 78$ after another half hour. At some uncharted time the patient had received phenylephrine $2 \mathrm{ml}$. intramuscularly and 2 minims intravenously, and later edrophonium $10 \mathrm{mg}$. intramuscularly and $3 \mathrm{mg}$. intravenously. The result of this medication was not noted. The patient was discharged two days later.

\section{CASE 2}

This patient was a 20 -year-old female admitted in 1958 with a known diagnosis of "Thomsen's disease" for which she was taking quinine tablets. She also was suffering from menorrhagia. She was taken to the operating room for a dilatation and curettage. The effect of the premedication of meperidine $100 \mathrm{mg}$. and hyoscine $0.4 \mathrm{mg}$. was not noted. The anaesthesia was induced with an unstated amount of thiopental, the blood pressure was not recorded. The pulse was noted 70,64 , and 64 . The anaesthetic course was reported "good" and the condition on leaving the operating room "good." In the recovery room the blood pressure was $120 / 80$, with respirations of 16 per minute. The pulse was 60,56 , and 52 . The patient returned to the ward with a blood pressure of $120 / 80$, a pulse of 60 , and respiration 20 ; nausea was noted. She was discharged 5 days later.

In September, 1959, she was admitted 7 months pregnant. During the next 6 weeks she was treated with ion exchange resins in an attempt to lower her abnormally high serum potassium. This was of no apparent benefit. When she was at term an induction was attemped with pitocin, which caused uterine spasm and a fall in foetal heart rate from 100 per minute to 20 per minute. This was treated with oxygen, and then the patient went into labour. She was given $15 \mathrm{mg}$. of morphine for relief of pain. At the time of delivery 4 hours later she received a pudendal block and nitrous oxide - trichlorethylene analgesia. The baby was slow to breathe and rated 6 on the Apgar scale. No ill-effects on the mother were noted.

\section{CASE 3}

This was a female who had been investigated and diagnosed in another hospital in December, 1958, at the age of 26 . She had been treated with quinine and phenothaizines without apparent benefit. She was admitted to this hospital in December, 1959, for investigation of backache and readmitted in February, 1960, with backache and stiffness in her 
hands. She was readmitted in July, 1961, with backache, stiff hands, and pain in the right foot attributed to the loss of the transverse arch. She was booked for surgical correction of this latter condition. Premedication of merperidine $50 \mathrm{mg}$., hyoscine $0.4 \mathrm{mg}$. was considered satisfactory on her arrival in the operating room. Anaesthesia was induced with thiopental $200 \mathrm{mg}$. and maintained with nitrous oxide - oxygen and halothane by a non-rebreathing system. During 50 minutes of anaesthesia the pulse and blood pressure remained stable and the condition good. The patient was awake 45 minutes after discontinuing anaesthesia. There were no postanaesthetic complications. She was discharged well on the seventh day.

\section{CASE $t$}

This was a man who had been admitted to another hospital in 1956 with a long history of epigastric pain, 20 pounds weight loss, and a confirmed duodenal ulcer. The preoperative medication was "Seconal" $96 \mathrm{mg}$. $1 \frac{1}{2}$ hours preoperatively, and meperidine $100 \mathrm{mg}$., hyoscine $0.4 \mathrm{mg}$. given in tramuscularly 45 minutes before operation. He was given a spinal anaesthetic with $20 \mathrm{mg}$. of tetracaine (Pontocaine ${ }^{\circledR}$ ). This was supplemented with thiopental 2.5 per cent in an initial dose of $12 \mathrm{ml}$. and a second dose of $8 \mathrm{ml}$., to a total of $500 \mathrm{mg}$. When surgery started he was given $50 \mathrm{mg}$. of meperidine and $25-\mathrm{mg}$. doses at 50 minutes, 65 minutes, 85 minutes, 115 minutes, and 155 minutes after the start of surgery, a total of $200 \mathrm{mg}$. Two hours after surgery: started a drip of succinylcholine 0.2 per cent was started. He also received 1 litre of blood and $750 \mathrm{ml}$. of intravenous fluid. The postoperative condition was considered good by the anaesthetist when the patient was taken to the recovery room at the conclusion of 4 hours 15 minutes of surgery. No complications were noted. A subtotal gastrectomy had been done. On arrival in the recovery room the patient showed some muscle spasm, he was cyanosed, and as he roused he was very uncooperative. Oxygen was started at 6 litres per minute. After $2 \frac{1}{2}$ hours in the recovery room the patient received a further $100 \mathrm{mg}$. of meperidine for restlessness, the nurses' notes state that this "settled him down."

He was admitted to this hospital in November, 1960, and the diagnosis of myotonia dy'strophia was made. He had minimal restrictive and obstructive defects of ventilation, plus a positive myotonia sign. He was brought to the operating room for a nephrectomy. The premedication of meperidine $50 \mathrm{mg}$. and hyoscine $0.5 \mathrm{mg}$. was considered satisfactory, with greater depression than had been anticipated. Induction with thiopental $100 \mathrm{mg}$. and succinylcholine $60 \mathrm{mg}$. was smooth, intubation easy, and recovery from the succinylcholine within the normal limits. He received a further dose of succinylcholine $40 \mathrm{mg}$. ten minutes later and atropine $0.6 \mathrm{mg}$. 25 minutes after induction for bradycardia. He was given $d$-tubocurare $9 \mathrm{mg}$. intravenously half an hour after induction. This produced more profound relaxation than usual. Anaesthesia was maintained with halothane - ether azeotrope in a semi-closed system. The operation lasted 1 hour and 10 minutes, the patient awakened 1 hour and 5 minutes. after admission to the recovery room, and returned to the ward in good condition.

He was readmitted in June, 1960, with a depressed fracture of the left malar eminence from a car accident. Blood pressure was good. The nurses' notes mentioned that the hand grips were strong and equal. He was brought to the operating room for reduction of the fracture. The premedication of $50 \mathrm{mg}$. of meperidine and $0.4 \mathrm{mg}$. of hyoscine was satisfactory. Anaesthesia was induced with an unstated amount of thiopental and maintained with thiopental and nitrous oxide - halothane in a semi-closed circle with an endotracheal tube. There was no mention of relaxants, and no record of vital signs. The blood pressure in the recovery room was $160 / 70$ and the pulse 80 . He was discharged two days later. There was no note of complications.

\section{CASE 5}

This was a 100 -pound 31 -year-old female who had been admitted to another hospital in 1957 with a haemorrhaging incomplete abortion. Her haematocrit on admission was 36.5 per cent. She received sodium amytal $196 \mathrm{mg}$. at bedtime and slept well. Premedication of morpine $15 \mathrm{mg}$. and hyoscine $0.4 \mathrm{mg}$. was considered adequate when she was brought to the 
operating room the next morning. No note of the preanaesthetic blood pressure, respiration, or colour was found. She received $5 \mathrm{ml}$. of 5 per cent thiopental intravenously. Anaesthesia was maintained with nitrous oxide - oxygen in a fractional rebreathing system. Her pulse was recorded at 84 and 88 , with respirations 20 per minute. Blood pressures were not recorded. Anaesthesia lasted 20 minutes. On arrival in the recovery room the blood pressure was $98 / 52$. Thirty minutes after admission nasal oxygen was started at 4 litres per minute and continued for half a hour. She returned to the ward after a $1 \frac{1}{2}$ hour stay in the recovery room. Her pressure on arrival at the ward was $94 / 60$. She ate her supper that night and there was no note of any complications.

She was admitted to this hospital in September, 1958, a typical patient with myotonia dystrophia. Medical treatment with Metacorten and ion exchange resins failed to produce benefit.

\section{CASE 6}

This was a 181-pound 44-year-old male who was admitted here in 1960 with symptoms of cholecystitis and obstructive jaundice. He appeared eunuchoid with all the stigmata of myotonia dystrophia except for cataracts. Chest expansion was limited by fixation of the thoracic cage. Medium-pitched rhonchi were audible throughout the posterior chest. The vital capacity was 2 litres, the maximum expiratory flow rate 60 litres per minute. Chest $\mathrm{X}$-rays showed partial atelectasis or bilateral basal pneumonitis. The history noted that his five brothers had died before the age of 50 and none had produced children. The patient was seen by the anaesthesia department and not considered a candidate for elective surgery.

He was readmitted in September, 1960, with a recurrence of symptoms and was most urgent in his plea for relief, accepting the increased risk of surgery and anaesthesia. Intensive medical treatment with positive pressure breathing, chest physiotheraphy, and antibiotic nebulization was given and his chest improved slightly. Chest X-ray's showed no improvement. Prior to operation his vital capacity was 1.6 litres.

The preoperative medication of meperidine $25 \mathrm{mg}$., atropine $0.6 \mathrm{mg}$. was considered satisfactory. Anaesthesia was induced with thiopental $300 \mathrm{mg}$. and succinylcholine to a total of $100 \mathrm{mg}$. Fasciculation was not noted, but relaxation was not adequate. On attempting intubation it was found that the patient's head could not be extended nor his mouth opened more than one inch. Multiple attempts at intubation were made requiring supplemental doses of succinylcholine to a total of $260 \mathrm{mg}$. Eventually he was intubated with a no. 9 cuffed endotracheal tube. Anaesthesia was maintained with cyclopropane and a trace of ether with relaxation provided by the succinylcholine drip 0.1 per cent. The surgeon had assured us prior to and during the operation that he would be as fast as possible and would appreciate the greatest relaxation that we could provide. For this reason relaxation was maintained with succinylcholine drip although after an hour conversion to a competitive blocking agent was contemplated. By the time surgery was completed in 2 hours and 35 minutes the patient had received a total of $1.3 \mathrm{gm}$. of succinylcholine. Respiration was inadequate. There was a marked improvement following $10 \mathrm{mg}$. of edrophonium bromide intravenously so he was given atropine $0.6 \mathrm{mg}$. and prostigmine $1 \mathrm{mg}$. intravenously, with immediate improvement in respiration. The patient was taken to the recovery room, where he arrived slightly cyanosed. He was able to respond and to breath deeply on instruction. He returned to the ward 1 hour and 10 minutes later, and intensive chest treatment was recommenced on the ward. Tracheotomy was considered but was not performed. X-rays indicated a possible atelectasis of the right middle lobe immediately postoperative. This responded to medical treatment, and he was discharged without further complications.

These patients responded to the premedication, as one could reasonably anticipate. Where barbiturates were used for bedtime sedation or preanaesthetic medication no unusual effects were noted. The response to thiopental was at no time noted to be abnormal. In case 1 the response of an $84 \frac{3}{4}$ pound woman to $500 \mathrm{mg}$. of thiopental for the first anaesthetic and $750 \mathrm{mg}$. for the second pro- 
cedure is not remarkable. Similarly case 4 , who received meperidine $100 \mathrm{mg}$. intramuscularly 45 minutes prior to a spinal anaesthetic and a further $200 \mathrm{mg}$. during the next 2 hours and 35 minutes of the procedure, in addition to $500 \mathrm{mg}$. of thiopental and a drip of succinylcholine, could not be called hypersensitive. It would appear that the spinal anaesthetic produced adequate relaxation for the first 2 hours. (There are of course doubts about a spinal that requires a "supplement" of $200 \mathrm{mg}$. of meperidine, $500 \mathrm{mg}$. of thiopental, and 0.2 per cent succinylcholine drip.) It is interesting to ponder the relationship of dystrophia myotonia, with its tendency to depolarization, to myasthenia gravis, which reacts in every respect like a partial curarization. If a small dose of curare will produce complete relaxation of a myasthenic patient, then by analogy a small dose of succinylcholine should produce complete depolarization and relaxation of a patient with dystrophia myotonia. Conversely, since myasthenics are improved by prostigmine, one would anticipate that myotonic patients would have their symptoms aggravated by prostigmine.

Based on examinations of the anaesthetic records of nine anaesthetics administered to six patients, the author agrees entirely with Kaufman that patients with myotonia dystrophia are not unduly susceptible to thiopental. We also concur that a preoperative assessment of lung function is important and that the pulmonary function should be at its best before anaesthesia is undertaken. However, these problems are not peculiar to myotonia dystrophia, but rather the myotonia patient should be considered as another sick patient requiring assistance with his respiration during and following surgery. The response to depolarizing relaxants in this series was entirely unremarkable. Neostigmine did not have any adverse effect.

In summary, then, it would seem that a patient with myotonia dystrophia should be given a good anaesthetic.

\section{REFERENCES}

1. Merritt. Textbook of Neurology, 2nd ed., p. 514. Philadelphia: Lea \& Febiger (1959).

2. DundeE, John W. Anaesth. \& Analg. 31: 257-262 (1952).

3. Kaufman, Leon. Proc. Roy. Soc. Med. 53 (3): 183-189 (March, 1960).

4. Taverner, D. Brit. J. Anaesth. 32: 514-518 (1960). See also: McClelland, R.M.A. Brit. J. Anaesth. S2: 81-88 (1960). 